\title{
EVALUATION OF PSYCHIATRIC DISABILITY AMONG PATIENTS WITH SCHIZOPHRENIA IN RELATION TO MARITAL STATUS: A CROSS-SECTIONAL STUDY
}

\author{
Rasamsetti Vijaya Kranthi', Chennamsetty Siva Kumar ${ }^{2}$
}

${ }^{1}$ Assistant Professor, Department of Psychiatry, Osmania Medical College, Hyderabad. ${ }^{2}$ Assistant Professor, Department of Psychiatry, Osmania Medical College, Hyderabad.

\section{ABSTRACT}

\section{BACKGROUND}

The marital adjustment is a process in which an individual or a couple modifies, adopts or changes their behaviour pattern and interaction to gain the maximum satisfaction in their relationship. Schizophrenia is a chronic mental illness associated with major disability in several spears of a person's functioning. Most of the previous studies shows that schizophrenia associated with adverse outcome on marriage. This study conducted to evaluate how disability due to schizophrenia related to marriage in these patients.

\section{AIM}

The study was undertaken to evaluate and correlate psychiatric disability in relation to marital status in patients with schizophrenia.

\section{MATERIAL AND METHODS}

It is a cross-sectional study in a tertiary care psychiatric hospital in 162 patients who was diagnosed of schizophrenia as per ICD - 10 criteria and on regular treatment for the past one year. Sample consists of three groups married, unmarried (never married) and single (widow, divorcee and single). IDEAS rating applied on all the subjects to evaluate disability and the result was analysed by t-test and ANOVA using SPSS 13.0 version.

\section{RESULTS}

Out of 162 patients with schizophrenia 81 married, 31 single and 50 unmarried. The mean disability score was (7.78) showing high disability in schizophrenia patients. Married patients group had more cases with mild disability scores and single and unmarried patients group had more cases with moderate-to-severe disability scores (Chi-square $=13.851$ and p-value $=0.008$ ). Mean disability score (9.12) was high in unmarried group. The marital status was significantly associated with disability (F-value $=3.622$ and pvalue $=0.029$ ). Males reported high disability than females, but gender was not showing significant association with disability. Both male and female married patients had less disability.

\section{CONCLUSIONS}

Schizophrenia patients were showing higher disability and majority (50\%) eligible for welfare benefits. Unmarried and single were having more disability and requires greater help from society and government. Community based assessment will be more helpful in planning future rehabilitation services to these patients in this deinstitutionalization scenario.

\section{KEYWORDS}

Disability, Marital status, Schizophrenia.

HOW TO CITE THIS ARTICLE: Kranthi RV, Kumar CS. Evaluation of psychiatric disability among patients with schizophrenia in relation to marital status: a cross sectional study. J. Evolution Med. Dent. Sci. 2016;5(55):3709-3715, DOI: $10.14260 /$ jemds/2016/851

\section{INTRODUCTION}

The origins of rehabilitation in psychiatry in the West can be traced to the Community Mental Health Movement. Prior to the 1950 s care of the mentally ill was primarily institution based and custodial in approach. Much has been written about the long-term deleterious effects of such care. ${ }^{1}$ It was assumed that people with major mental illness should be helped to maintain themselves in the community. Although, deinstitutionalization was a positive step, it was too idealistic. What was achieved was merely a shift in the locus rather than

Financial or Other, Competing Interest: None.

Submission 20-06-2016, Peer Review 02-07-2016,

Acceptance 04-07-2016, Published 08-07-2016.

Corresponding Author:

Dr. Rasamsetti Vijaya Kranthi,

First Floor, Plot No: 65, H. No: 8-3-167/A/65,

Lane Opp. Municipal Water Tank,

Vikaspuri Colony, Erragadda,

Hyderabad-500018.

E-mail: dr.vijayakranthi@gmail.com

DOI: $10.14260 /$ jemds $/ 2016 / 851$ the focus of care. The various issues related to deinstitutionalization have been reviewed by Lamb. ${ }^{2}$ However, the movement highlighted the fact that pharmacotherapy alone was inadequate.

A comprehensive system of care, encompassing a variety of therapeutic approaches is needed to enable the mentally ill patient to function optimally and live in the community. Epidemiological evidence indicates that Schizophrenia with its low incidence and high prevalence is a condition affecting people typically in early adulthood and in some cases lasting for the rest of their lives. The training of mental health professionals and the delivery of mental health care has, hitherto, been centred around the handling of acute episodes of illness. However, in the case of chronic illness what is required is a longitudinal approach providing lifelong care. ${ }^{3}$

Disability is defined as "the outcome or result of a complex relationship between an individual's health condition and personal factors and of the external factors that represent the circumstances in which the individual lives" WHO-ICF 
(International Classification of Functioning, Disability and Health, 2002) ${ }^{4}$. Symptoms and functioning represent two distinct components of an individual's psychiatric presentation. ICF defines functioning as general aspects of a person's body functions, activities and social participation. Disability indicates problems in any one of these dimensions. When considering disability, one also needs to characterize an individual's background and life situation. These are called "contextual factors" in ICF and include environmental and personal factors that may have an impact on an individual's health. Disability is a final common pathway on which multiple influences converge; biological factors, individual factors such as comorbid substance abuse, cognitive impairment, extraindividual factors such as social environment, stigma, social support, etc.

Schizophrenia is the ninth leading cause of disability among the major causes of disability.5,6 Schizophrenia is the most severe among all the mental illnesses drastically affecting various areas of life. This disorder disrupts the day-to-day life functioning of the person. Self-care, interpersonal relationships, social involvement and vocational life are all affected. 7 The reason for considering disruption in social functioning as a severe disability is due to the inability in maintaining a minimum level of social involvement. A person with Schizophrenia finds it extremely difficult to initiate and pursue any form of social activity. Cognitive deficits have been identified as one of the prominent characteristics of Schizophrenia. ${ }^{8}$ Studies show that these deficits remain consistent for a longer period. ${ }^{9}$

World Health Organization global burden of disease 2000 reports Schizophrenia causes a high degree of disability and accounted for $1.1 \%$ of the total Disability-Adjusted Life Years (DALYs) and $2.8 \%$ of Years of Life Lived with Disability (YLDs) and it is the seventh leading cause of YLDS in the world. In a recent 14-country study on disability found that Schizophrenia accounted for high economic cost. There are very few Indian studies, which have specifically addressed the disability associated with Schizophrenia. ${ }^{10}$

Marriage is a social process requiring certain social abilities for it to be successful. A social process in which two individuals relate on a personal and intimate basis, pledging to share a life together. In several societies including in India, it is sanctified and glorified and is still largely a commitment for life. The process leading to marriage is strongly influenced by cultural norms and social factors, which impact the selection of spouse. Mental disorders and problems in marriage are closely linked, though there is a controversy about the sequence.11,12 Most of the previous studies found that Schizophrenia was associated with considerable disruption of a person's personal, marital, social and occupational functioning. Therefore, reduction of such abilities has been associated with a low marital rate, especially in men. The issue of marital status vis-a-vis outcome of Schizophrenia has been addressed.13,14,15 The information available on the subject of marital rates is restricted to speculation on the possible factors associated with it. 16 and is derived primarily from western cultures, where the socio-cultural factors related to marriage are vastly different from those in countries such as India. Studies in India have shown that families are more tolerant of deviant behaviour and more willing to take care of the ill member. ${ }^{17}$ However, with increasing urbanization, lifestyles are undergoing rapid change. The nuclear family system and shrinking social networks combined with increasing financial strain is making it more difficult to care for an ill relative. Studies have documented that distress and burden of caring for an ill relative are high. ${ }^{18}$

Marital status does not amount to the causes of mental illness. The marital status is a categorical risk factor in mental illness. Previous studies were showing that married persons have the least chances of acquiring major mental disorders, and divorced or widowed persons have the greatest chances. Single persons have less of a chance of becoming mentally ill than divorced or widowed persons, but a greater chance than married persons. Interestingly, all outcome variables be they clinical, occupational or social, were strongly associated with marital outcome. In view of association of Schizophrenia with poor marital outcome and clinical outcome variables, this study was conducted in order to evaluate the relation between marital status with disability due to Schizophrenia.

\section{MATERIAL AND METHOD}

This study was undertaken at Government Hospital for Mental Care/Andhra Medical College, Visakhapatnam - a premier University Hospital exclusively for psychiatric patient care and has seven units and out-patient department and a bed strength of 300 in-patients. Patients who were diagnosed as Schizophrenia per ICD-10 criteria and under remission for the past minimum one year with regular antipsychotic medication treatment were included in this study. The sample consists of age group 18-65 years of both genders. Subjects who had schizoaffective disorder, mental retardation, $\mathrm{H} / \mathrm{o}$ substance abuse, epilepsy, organic brain pathology, other chronic diseases and other physical disabilities were excluded.

The sample $(n=162)$ consists of 90 men $(56 \%)$ and 72 women (44\%). The ages ranged between 18-65 years; the mean age being $36.84 ; 25 \%$ were uneducated and $56 \%$ passed school education and $19 \%$ passed college education. Majority (85\%) were among Hindu religion. Most of patients (55\%) belonged to rural area. Sample consists of three groups married, unmarried (never married) and single (married previously, but currently single and this group also included those who were separated, divorced and widowed). Out of 162 patients 81 married, 31 single and 50 unmarried. The disability scores assessed in these three groups by applying Indian Disability Evaluation and Assessment Scale (IDEAS). The disability scores and severity of disability compared among these three marital groups and genders male and female groups.

\begin{tabular}{|c|c|c|c|c|}
\hline & & Count (\%) & Chi-Square & p-value \\
\hline Gender & & & & \\
\hline & Male & $90(56 \%)$ & 2.371 & 0.306 \\
\hline & Female & $72(44 \%)$ & & \\
\hline Religion & & & & \\
\hline & Hindu & $138(85 \%)$ & 4.149 & 0.386 \\
\hline & Christian & $16(10 \%)$ & & \\
\hline & Muslim & $8(5 \%)$ & & \\
\hline & & & & \\
\hline & Rural & $89(55 \%)$ & 4.571 & 0.334 \\
\hline & Semi urban & $24(15 \%)$ & & \\
\hline Education & Urban & $49(30 \%)$ & & \\
\hline & & & & \\
\hline & Uneducated & $41(25 \%)$ & 5.263 & 0.261 \\
\hline & School & $91(56 \%)$ & & \\
\hline & College & $30(19 \%)$ & \\
\hline \multicolumn{7}{|c|}{ Table 1: } \\
\hline
\end{tabular}

Table 1: Depicts Socio-demographic Profile of the Sample 


\section{Statistical Analysis}

Socio-demographic profile frequencies are calculated and categorical data was analysed using chi-square test. Parametric test t-test and ANOVA were used to compare data between groups. The data was analysed using SPSS 19 version.

\section{RESULTS}

In 2001 the Rehabilitation Committee of the Indian Psychiatric Society developed a tool for assessing psychiatric disability due to mental illness known as Indian Disability Evaluation and Assessment Scale (IDEAS). ${ }^{19}$ The alpha value was 0.8682 indicating good internal consistency between the items. It has good criterion validity and at face value, the instrument appeared to be measuring the desired qualities. IDEAS was field tested in 9 centres all over India and has now been gazetted by the Ministry of Human Resources and Empowerment, Government of India, as the recommended instrument to measure psychiatric disability. A few states in the country are using it to certify psychiatric disability and accord benefits under the welfare schemes to the disabled.

In present study married group consists of 81 subjects, among which 38 (47\%) had mild and 40 (49\%) had moderate and $3(4 \%)$ had severe disability scores. Previously married but currently single group consists of 31 subjects among which $16(52 \%)$ had mild and 9 (29\%) had moderate and 6 (19\%) had severe disability scores. Unmarried group consists of 50 subjects among, which 14 (28\%) had mild and 28 (56\%) had moderate and $8(16 \%)$ had severe disability scores. It shows that more mild disability scores were noted in married people and more moderate-to-severe disability scores noted in single and unmarried group. The disability was more in single and unmarried group. Chi-square value is 13.851 and p-value is 0.008 . So the difference observed in distribution of number of subjects in mild, moderate and severe disability categories among married, single and unmarried group is statistically significant.

\begin{tabular}{|c|c|c|c|c|c|}
\hline & $\begin{array}{c}\text { Mild } \\
\text { Disability }\end{array}$ & $\begin{array}{c}\text { Moderate } \\
\text { Disability }\end{array}$ & $\begin{array}{c}\text { Severe } \\
\text { Disability }\end{array}$ & $\begin{array}{c}\text { Chi-square } \\
\text { value }\end{array}$ & $\begin{array}{c}\text { p- } \\
\text { value }\end{array}$ \\
\hline Married & $38(47 \%)$ & $40(49 \%)$ & $3(4 \%)$ & & \\
\hline Single & $16(52 \%)$ & $9(29 \%)$ & $6(19 \%)$ & 13.851 & 0.008 \\
\hline Unmarried & $14(28 \%)$ & $28(56 \%)$ & $8(16 \%)$ & & \\
\hline
\end{tabular}
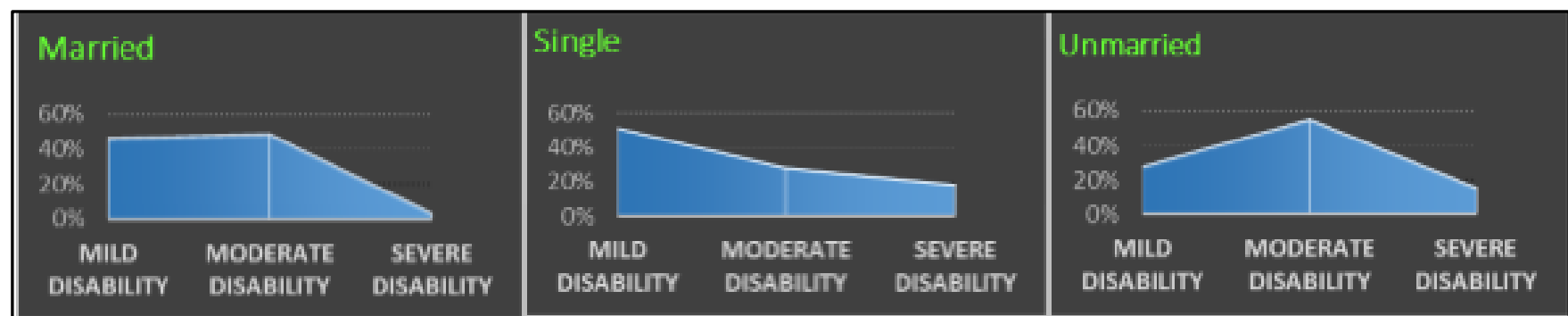

The mean disability scores of total sample is 7.78 , which is high. The mean disability score of married group is 7.14 and single group is 7.29 and unmarried group is 9.12. Unmarried group had high disability scores. The disability scores were compared among married, single and unmarried groups using ANOVA. F-value obtained is 3.622. $\mathrm{P}$ value is .029 . So the difference observed in disability scores among groups is statistically significant. Unmarried Schizophrenia patients reported high disability scores.

\begin{tabular}{|c|c|c|c|}
\hline & Mean Disability Scores & F-value & p-value \\
\hline Married & 7.14 & & \\
\hline Single & 7.29 & 3.622 & 0.029 \\
\hline Unmarried & 9.12 & & \\
\hline
\end{tabular}

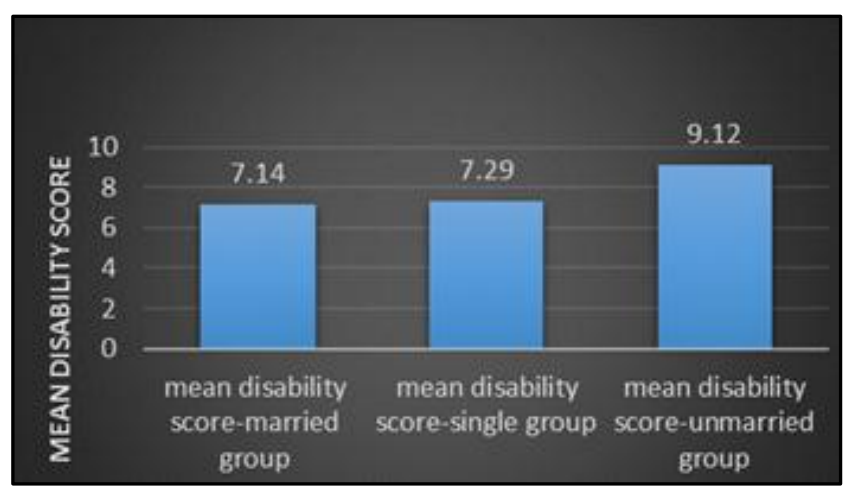

Total patients in male group is 90, among which 34 (38\%) had mild and $44(49 \%)$ had moderate and 12 (13\%) had severe disability scores. Female group with a total of 72 patients showed 35 (39\%) mild and 30 (33\%) moderate and had $7(8 \%)$ severe disability scores. Male group had more number of patients with severe disability.

\begin{tabular}{|c|c|c|}
\hline & Male & Female \\
\hline Mild disability & $34(38 \%)$ & $35(39 \%)$ \\
\hline Moderate disability & $44(49 \%)$ & $30(33 \%)$ \\
\hline Severe disability & $12(13 \%)$ & $7(8 \%)$ \\
\hline
\end{tabular}
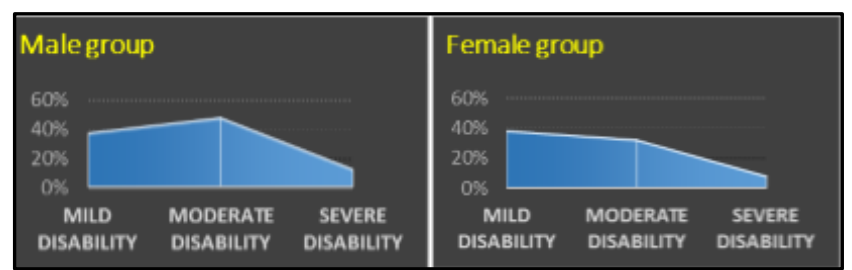

Among 43 married male patients 20 (46.5\%) had mild, 20 (46.5\%) moderate and $3(7 \%)$ severe disability. Among 7 single males 4 (57\%) had mild, 2 (29\%) moderate and $1(14 \%)$ severe disability. Of the 40 unmarried males 10 (25\%) had mild, 22 (55\%) moderate and 8 (20\%) severe disability. Married males had higher count of mild disability cases, whereas single and unmarried groups had more cases with moderate-to-severe disability. The chi-square value is 6.879. $\mathrm{P}$ 
value is 0.142 . Among male group the difference observed in number of patients in married, single and unmarried is not statistically significant.

\begin{tabular}{|c|c|c|c|c|c|}
\hline & Mild Disability & Moderate Disability & Severe Disability & Chi-Square value & p-value \\
\hline Male married & $20(46.5 \%)$ & $20(46.5 \%)$ & $3(7 \%)$ & & \\
\hline Male single & $4(57 \%)$ & $2(29 \%)$ & $1(14 \%)$ & 6.879 & 0.142 \\
\hline Male unmarried & $10(25 \%)$ & $22(55 \%)$ & $8(20 \%)$ & & \\
\hline
\end{tabular}
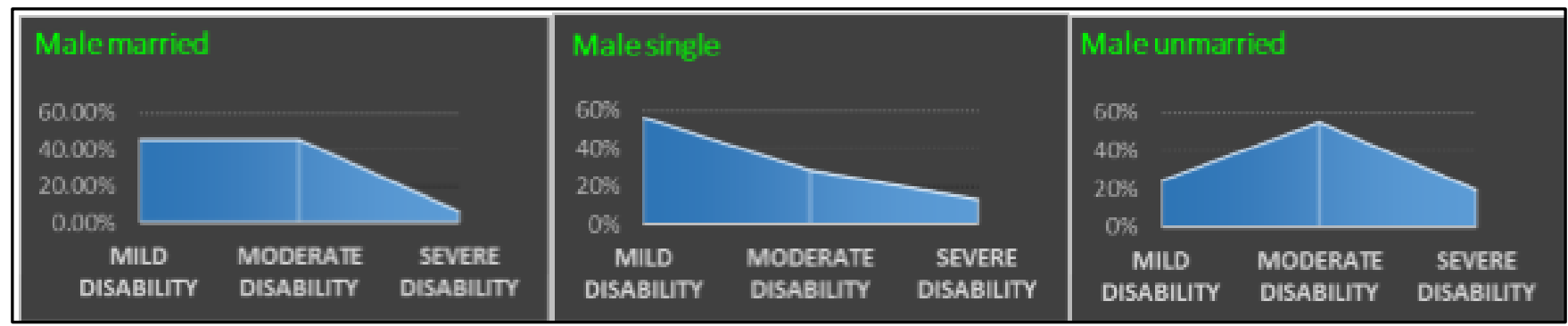

Among the 38 married females 19 (50\%) showed mild, 18 $(47 \%)$ moderate and $1(3 \%)$ severe disability. Female single group 24 showing 12 (50\%) mild, 7 (29\%) moderate and 5 $(21 \%)$ severe disability. Female unmarried group 10 showing 4 (40\%) mild, 5 (50\%) moderate, 5 (50\%) severe disability. More number of married females had mild disability scores.
Single and unmarried females having more number of moderate-to-severe disability scores. The chi-square value is 6.554 and $p$-value is 0.161 . So the difference observed among female married, single and unmarried patients is not statistically significant level.

\begin{tabular}{|c|c|c|c|c|c|}
\hline & Mild Disability & Moderate Disability & Severe Disability & Chi-Square value & p-value \\
\hline Female married & $19(50 \%)$ & $18(47 \%)$ & $1(3 \%)$ & & \\
\hline Female single & $12(50 \%)$ & $7(29 \%)$ & $5(21 \%)$ & 6.554 & 0.161 \\
\hline Female unmarried & $4(40 \%)$ & $5(50 \%)$ & $5(50 \%)$ & & \\
\hline
\end{tabular}
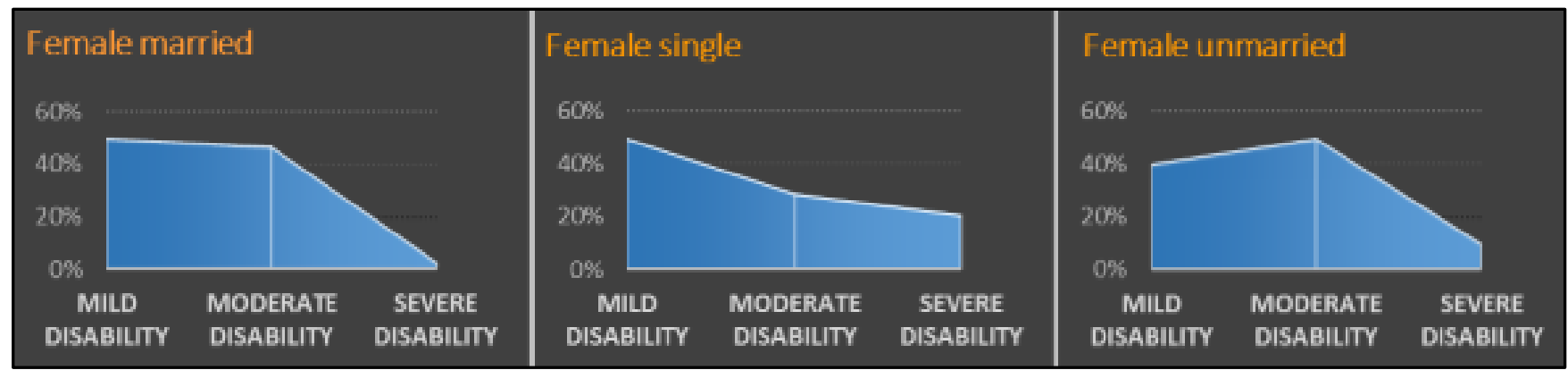

\section{DISCUSSION}

Discussing marriage in India. ${ }^{20}$ indicated that marriage in this predominantly Hindu society is often undertaken in order to fulfil one's social and religious duties ("Dharma") rather than for other purposes. Remaining single, especially for women can almost be a stigma in Indian societies and there is often undue pressure on the head of the family to get their female members married. Social avoidance of the patient by their close network and by the patient of them are both associated with poor marital outcome. Marriage, being a social process, may depend on the ability to relate socially for its success. A previous study show prevalence of Schizophrenia may be higher among men than women and $52.8 \%$ of patients are single. ${ }^{21}$ One Indian study reports that in Schizophrenia patients majority of male subjects were unmarried (62.1\%) and an equal proportion of female subjects were married and unmarried (35.1\% each) and $18.9 \%$ of the female subjects were either separated or divorced. Only $8.3 \%$ of male subjects were either separated or divorced. There was a statistically significant difference (Chi-square $=25.27, \mathrm{df}=4, \mathrm{P}<0.05$ ) in the marital status of the male and female study subjects. All the female subjects not gainfully employed and were financially dependent on the family and significant greater proportion of them were either divorced or separated. This was reflection of the impact of their illness on marital status. However, majority of males still manage to continue in marital relation. ${ }^{22}$ The study by Kujur et $\mathrm{al}^{23}$ also observed a significant difference in marital status of male and female patients with Schizophrenia with majority $(57.7 \%)$ of women separated from their husbands. Thara and Srinivasan. ${ }^{24}$ studied marital rates and their correlates in a cohort followed up for 10 years; a high rate of marriage was found in patients and majority of the marriages were intact at followup. Present study shows slightly more female $(53 \%)$ married in comparison to male (48\%).

Studies from the west have documented moderate disability in most of patients diagnosed with Schizophrenia irrespective of the setting. ${ }^{25}$ Indian studies have revealed the disability among patients with Schizophrenia to moderate-tosevere as early as 2-5 years after illness onset. ${ }^{26}$ In a study 
from Assam, 64\% of patients suffering from Schizophrenia and $30 \%$ of those suffering from bipolar affective disorder had severe disability as per the IDEAS. ${ }^{27}$ Also another study shows that the disability tends to remain stable over time with minimal fluctuations. ${ }^{28}$ However, an Indian study among nontreatment seeking individuals in a community setting found mild disability as the most common. ${ }^{29}$ One Indian study of patients seeking disability certification showing moderate disability was most common followed by severe disability. ${ }^{22}$ Patients with Schizophrenia reported significant greater disability on each of the disability domains of the WHODAS-II except in the "getting around" domain. ${ }^{30}$ Hospital based study in China reported $73 \%$ patients with Schizophrenia had clinically significant disability. ${ }^{31}$ The current study consists of 90 males and 72 females; slightly male predominance in the sample. The mean disability score was 7.78 showing Schizophrenia was associated with high disability and majority (50\%) eligible for welfare and benefits and they need support from family members, mental health professionals, the community, Government and non-Government organizations. Married patients had less disability when compared to single and unmarried group. The disability scores significantly high in unmarried and single group.

A study on adolescent onset of Schizophrenia found no significant differences between males and females, but there was a trend toward a more serious course in males. ${ }^{32}$ Chaves et $\mathrm{l}^{33}$ found that males had higher levels of disability than females; but they reported no differences in social role performance between the genders. In contrast, an Indian study by Radha et $\mathrm{al}^{34}$ reported that women were more disabled than men. Considering the quality of life, this study shows males had a significantly better quality of life than females with regard to all the domains: physical, psychological $(\mathrm{P}=.000)$; and social $(\mathrm{P}=.003)$. This result is in contrast to the results found in the studies by Atkinson et al 35 and Carpiniello et al. $^{36}$ The results with regard to the difference between genders in the QOL in Schizophrenia have been inconsistent and varying from place to place as reported by Vandiver. ${ }^{37}$ No significant difference was found in the domain of environment; the results in the study by Alptekin et al ${ }^{8}$ were similar to these. Shankar et al $^{34}$ reported the gender differences in disability among married patients with Schizophrenia. The study sample included 30 married patients of both sexes. Disability was evaluated using the modified version of the Disability assessment schedule. Results indicated that women were more disabled than men, in contrast to the findings from literature elsewhere. Thara and Joseph. ${ }^{28}$ compared the course in males and females and found that males had more disability, especially in the area of occupational functioning. The current study also noted more male patients $(62 \%)$ in comparisons to female (41\%) qualify for welfare benefits and help.

An unemployed schizophrenic male is doubly stigmatized and there is a lot of pressure on him to work. This is clearly reflected in the relationships both of being unemployed and of suffering a drop in economic status with outcome of marriage. In men, however, employment and occupation are critical necessities for getting married. In all developing countries where no disability benefits are accorded to the mentally ill, occupational status and profile greatly impact the lives of the patients and their families. This finding is similar to earlier studies, which demonstrated that many patients never married and were unemployed may reflect their deficits when interacting and coping with their human, social and physical environment and the complexity of modern society. ${ }^{38}$

As described by WHO, the concept of QOL is centered on the social and cultural environment of the individual. It is possible that various factors such as employment and family support reduce disability due to Schizophrenia in developing countries like India. Thus, there are inconsistent results about differences in levels of disability and QOL between genders in Schizophrenia and the differences depend more on social conditions.

In conclusion schizophrenia associated with high disability $(50 \%)$ and marital status had significant association with disability. Unmarried and single patients need great help from society and government.

\section{LIMITATIONS}

The results of the current study should be interpreted in the background of following limitations that may have affected the observations.

Current study, based exclusively on hospital based outpatient sample and therefore may not be the representative sample of patients in community.

All the variables were assessed cross-sectional; hence, answers to cause-effect relationship between variables cannot be given. Longitudinal studies should be carried out to look for correlations between changes in impact (Variables) with changes in severity of illness, type of treatment, etc. to answer questions regarding causal connections.

The sample size may be regarded as small and hence generalization of our findings to all types of patients is not possible.

\section{FUTURE DIRECTIONS AND CONCLUSIONS}

Attempts to improve the fate of the mentally disabled, especially in developing countries like India, face many obstacles. Stigmatization and discrimination are factors that come in the way of mentally ill receiving full disability benefits. People may have preconceived notions about the mentally ill that these people are lazy or dangerous. These will have important consequences on how individuals come to see themselves and lower their self-esteem (Self-stigmatization) which may worsen their disability. The levels of knowledge of mental illness do not correlate with discriminatory attitudes. Even a proportion of medical personnel who are well informed are not tolerant towards the mentally ill. Consequences of discrimination include increasing vulnerability to disability, magnifying the impact of illness, depriving care and treatment.

- There needs to be more research on factors associated with disability and psychiatric disorders.

- The disabled should demand benefits; we should remember that family has the prime responsibility to look after disabled and get the benefits due to them.

- Information regarding disability needs to be disseminated far and wide across the country.

- The attitude of a professional needs to change.

- Strong encouragement and assistance needs to be given to people with mental disability and their representatives to form organizations.

- The voice of the disabled needs to be recognized by the government.

- Lacunae in mental health laws include need to periodically review existing legislation and plan 
amendments or bring in new legislation from time to time.

\section{REFERENCES}

1. Wing JK, Brown GW. Institutionalism and schizophrenia: a comparative study of three mental hospitals 19601968. Psychological Medicine 1971;1(2):182-3.

2. Lamb HR. Deinstitutionalization at the crossroads. Hosp Community Psychiatry 1988;39(9):941-5.

3. Mechanic D. Emerging trends in research and social psychiatry: accomplishments and future prospects. In: Pichot P (ed). Epidemiology and community psychiatry. Plenum press, New York 1985.

4. Dahl TH. International classification of functioning, disability and health: an introduction and discussion of its potential impact on rehabilitation services and research. J Rehabil Med 2002;34(5):201-4.

5. Murray CJL, Lopez AD. A comprehensive assessment of mortality and disability from diseases, injuries, and risk factors in 1990 and projected to 2020. In: Murray CJL, Lopez AD (eds). The global burden of disease. Vol. 1. Cambridge, MA: Harvard University Press 1996.

6. Thirthalli J, Venkatesh BK, Naveen MN, et al. Do antipsychotics limit disability in schizophrenia? A naturalistic comparative study in the community. Indian Journal of Psychiatry 2010;52(1):37-41.

7. Tara R. Measurement of psychiatric disability. Indian J Med Res 2005;121(6):723-24.

8. Alptekin K, Akvardar Y, Akdede KBB, et al. Is quality of life associated with cognitive impairment in schizophrenia? Prog Neuropsychopharmacol Biol Psychiatry 2005;29(2):239-44.

9. Krishnadas R, Moore BP, Nayak A, et al. Relationship of cognitive function in patients with schizophrenia in remission to disability: a cross-sectional study in an Indian sample. Annals of General Psychiatry 2007;6:19.

10. World Health Organization Report. Chapter 2: Burden of mental and behavioural disorders 2001.

11. Kreitman N. Married couples admitted to mental hospital. The British Journal of Psychiatry 1968;114(511):699-718.

12. Rössler RA, Fätkenheuer B, Löffler W, et al. Is age of onset in schizophrenia influenced by marital status? Some remarks on the difficulties and pitfalls in the systematic testing of a simple question. Soc Psychiatry Psychiatr Epidemiol 1992;27(3):122-8.

13. Seeman MV. Current outcome in schizophrenia: women vs men. Acta Psychiatr Scand 1986;73(6):609-17.

14. León CA. Clinical course and outcome of schizophrenia in Cali, Colombia. A 10-year follow-up study. J Nerv Ment Dis 1989;177(10):593-606.

15. Thara R, Rajkumar S. Gender differences in schizophrenia. Schizophrenia Research 1992;7(1):6570.

16. Ritsner M, Sherina O, Ginath Y. Genetic epidemiological study of schizophrenia: reproduction behaviour. Acta Psychiatrica Scandinavica 1992;85(6):423-9.

17. Leff J, Wig NN, Ghosh A, et al. Expressed emotion and schizophrenia in north India. III. Influence of relatives expressed emotion on the course of schizophrenia in Chandigarh. Br J Psychiatry 1987;151:166-73.
18. Gopinath PS, Chaturvedi SK. Distressing behaviour of schizophrenics at home. Acta Psychiatr Scand 1992;86(3):185-8.

19. Indian Disability Evaluation and Assessment Schedule. Rehabilitation committee of Indian psychiatric society 2001:1-13.

20. Kapadia KM. Marriage and family in India. $3^{\text {rd }}$ edn. Oxford University Press, Delhi 1972.

21. Alem A, Kebede D, Fekadu A, et al. Clinical course and outcome of schizophrenia in a predominantly treatmentnaive cohort in rural Ethiopia. Schizophrenia Bulletin 2009;35(3):646-54

22. Balhara YPS, Verma R, Deshpande SN. A study of profile of disability certificate seeking patients with schizophrenia over a 5 year period. Indian Journal of Psychological Medicine 2013;35(2):127-34.

23. Kujur NS, Kumar R, Verma AN. Differences in levels of disability and quality of life between genders in schizophrenia remission. Ind Psychiatry J 2010;19(1):50-54.

24. Srinivasan TN, Thara R. How do men with schizophrenia fare at work? A follow-up study from India Schizophrenia Research 1997;25(2):149-54.

25. Parker G, Hadzi-Pavlovic D. The capacity of a measure of disability (the LSP) to predict hospital readmission in those with schizophrenia. Psychol Med 1995;25(1):15763.

26. Mohan I, Tandon R, Kalra H, et al. Disability assessment in mental illnesses using Indian disability evaluation assessment scale. Indian J Med Res 2005;121:759-63.

27. Chaudhury PK, Deka K, Chetia D. Disability associated with mental disorders. Indian J Psychiatry 2006;48(2):95-101.

28. Thara R, Joseph AA. Gender differences in symptoms and course of schizophrenia. Indian J Psychiatry 1995;37(3):124-8.

29. Kumar SG, Das A, Bhandary PV, et al. Prevalence and pattern of mental disability using Indian disability evaluation assessment scale in a rural community of Karnataka. Indian J Psychiatry 2008;50(1):21-3.

30. Akinsulore A, Mapayi BM, Aloba 00, et al. Disability assessment as an outcome measure: a comparative study of Nigerian outpatients with schizophrenia and healthy control. Ann Gen Psychiatry 2015;14:40.

31. Zhou Y, Zhou R, LI W, et al. Controlled trial of the effectiveness of community rehabilitation for patients with schizophrenia in Shanghai, China. Shanghai Archives of Psychiatry 2015;27(3):167-74.

32. Fleischhaker C, Schulz E, Tepper K, et al. Long-term course of adolescent schizophrenia. Schizophrenia Bulletin 2005;31(3):769-80.

33. Chaves AC, Seeman MV, Mari JJ, et al. Schizophrenia: impact of positive symptoms on gender social role. Schizophrenia Research 1993;11(1):41-45.

34. Shankar R, Kamath S, Joseph AA. Gender differences in disability: a comparison of married patients with schizophrenia. Schizophrenia Research 1995;16(1):1723. 
35. Atkinson $\mathrm{M}$, Zibin $\mathrm{S}$, Chuang $\mathrm{H}$, et al. Characterizing quality of life among patients with chronic mental illness: a critical examination of the self-report methodology. American Journal of Psychiatry 1997;154(1):99-105.

36. Carpiniello B, Pinna F, Tusconi M, et al. Gender differences in remission and recovery of schizophrenic and schizoaffective patients: preliminary results of a prospective cohort study. Schizophrenia Research and Treatment, Article ID 576369, 2012;2012:8.
37. Vandiver VL. Quality of life, gender and schizophrenia: a cross-national survey in Canada, Cuba and USA. Community Ment Health J 1998;34(5):501-11.

38. Solanki RK, Singh P, Midha A, et al. Schizophrenia: impact on quality of life. Indian J Psychiatry 2008;50(3):181-6. 